\title{
On-Line Evidence for Context Use by Right-Brain-Damaged Patients
}

\author{
Carol L. Leonard and Shari R. Baum \\ McGill University
}

\begin{abstract}
- The ability of right-brain-damaged (RBD) patients to use on-line contextual information in a word-monitoring task was examined. Subjects were required to monitor for target words in the contexts of both normal and semantically anomalous sentences. Similar to previous studies with normals (e.g., Marslen-Wilson \& Tyler, 1980), the semantic integrity of the context was influential in the word-recognition process. Importantly, the RBD patients performed similarly to normals in
\end{abstract}

showing context effects. These results were interpreted as substantiating the findings of Leonard, Waters, and Caplan (1997a, 1997b) that RBD patients do not present with a specific deficit in the use of contextual information. The results are discussed in terms of proposals that suggest that an impaired ability to use contextual information by RBD patients may be a function of increased processing demands.

\section{INTRODUCTION}

The issue of cerebral lateralization for communicative competence has provoked much research. The current view is that the left hemisphere is dominant for language in most right-handers, whereas the right hemisphere exerts an important influence at the level of discourse processing. Such a view is grounded in research indicating that right-brain-damaged (RBD) individuals frequently present with impairments in the processing of a variety of discourse-level phenomena (for reviews see Brownell, Gardner, Prather, \& Martino, 1995; Joanette, Goulet, \& Hannequin, 1990). For example, deficits have been demonstrated by RBD patients in the production and comprehension of narratives (e.g., Gardner, Brownell, Wapner, \& Michelow, 1983; Hough, 1990; Joanette \& Goulet, 1990; Schneiderman, Murasugi, \& Saddy, 1992), the processing of nonliteral forms of language, such as metaphors (e.g., Brownell, Simpson, Bihrle, Potter, \& Gardner, 1990), idioms (Van Lancker \& Kempler, 1987), verbal irony (Kaplan, Brownell, Jacobs, \& Gardner, 1990), and indirect speech acts (e.g., Weylman, Brownell, Roman, \& Gardner, 1989), and in understanding humor (e.g., Bihrle, Brownell, Powelson, \& Gardner, 1986). Some researchers (e.g., Gardner et al., 1983) have suggested that difficulty in the use of contextual information by RBD patients to process language may account for such seemingly diverse discourse-level impairments.

Recently, Leonard, Waters, and Caplan (1997a, 1997b) systematically tested this proposal by examining the ability of RBD patients to use contextual information to

resolve ambiguous pronouns at the level of the single sentence (in terms of the integration of information between clauses) and at the level of a minimal discourse (i.e., two sentence passages). In the first experiment of Leonard et al. (1997a), subjects were presented with sentences of the form NP1 Verb(ed) NP2 because Pronoun Reason (e.g., Mark confessed to Paul because he wanted forgiveness) and were required to indicate the referent of the pronoun with a button press. The stimuli were based on those used by Caramazza, Grober, Garvey, and Yates (1977) in which the verbs in the sentences naturally biased the assignment of the pronoun to either the first or second noun phrase. In some cases the assignment of the pronoun was consistent with the bias of the verb (as in the example given above); in other cases it was inconsistent with the verb's bias (e.g., Mark confessed to Paul because be offered forgiveness). Caramazza et al. (1977) found that reaction times to determine the preferred referent of a pronoun were faster to verb-consistent than verb-inconsistent sentences. Leonard et al. (1997a) argued that such a pattern of response was evidence for the ability to integrate contextual information across clauses, in that the inconsistency could only be noted, and thus reaction times decreased, if the information in the second clause was interpreted with relation to that in the first clause. In Leonard et al. (1997a), it was found that the RBD patients were similar to normals in responding faster to verbconsistent than to verb-inconsistent sentences, thereby providing evidence for the ability of RBD patients to use contextual information at the level of the single sentence. 
In the second experiment of Leonard et al. (1997a), the same stimuli were used as those in the first experiment, with one alteration-the addition of a leading sentence that supported the disambiguation of the pronoun (e.g., Mark knew that Paul was an understanding priest and would grant absolution. Mark confessed to Paul because be offered forgiveness). Contextual effects for both the RBD and normal groups were found in that reaction times were faster to sentences preceded by a supportive linguistic context than to those presented in isolation. These results were interpreted as evidence for the ability of RBD patients to use contextual information at the level of a minimal discourse-a claim that was further supported by the findings of Leonard et al. (1997b). In that investigation, using stimuli from Hirst and Brill (1980), it was found that reaction times to determine the preferred referent of an ambiguous pronoun were faster to sentences with a clearly specified referent based on general world knowledge (e.g., Henry spoke at a meeting while Jobn drove to the beach. He brought along a surfboard) than to those that were more ambiguous (e.g., Henry spoke at a meeting while Jobn drove to the beach. He looked toward a friend) for both the normal and RBD groups. Thus, contrary to initial expectations, the results of both investigations by Leonard et al. (1997a, 1997b) were consistent in demonstrating that RBD patients can use contextual information at least at the level of the single sentence and a minimal discourse.

In an attempt to explain the discrepancy in results between these investigations and those studies that have suggested an impairment in the use of contextual information by RBD patients (e.g., Gardner et al., 1983; Schneiderman et al., 1992), the explanation offered by Tompkins and her colleagues (Tompkins, 1990, 1991; Tompkins, Boada, \& McGarry, 1992; Tompkins, Bloise, Timko, \& Baumgaertner, 1994) was invoked. They have argued that RBD individuals' apparent difficulty in using context in language processing is a function of increased processing demands and not a deficit in the use of contextual information per se. They have pointed out that the tasks that have been used in such studies (e.g., story retelling) have necessitated effortful processing. In contrast, when on-line tasks that promote automatic processing, such as word-monitoring tasks, are used, Tompkins has found intact knowledge of metaphoric language (Tompkins, 1990) and idiomatic expressions (Tompkins et al., 1992)-discourse-level knowledge that has been identified as impaired in other studies (e.g., Brownell et al., 1990). Additional evidence for differential responding according to processing demands by RBD patients has also been found in the investigation of semantic processing impairments. Gagnon, Goulet, and Joanette (1994) found evidence for a lexical semantic impairment in RBD patients when engaged in a semantic judgment task (i.e., off-line, effortful) but not in a lexical decision task (i.e., on-line, automatic). Leonard et al. (1997a, 1997b) argued that the tasks used in their experiment also promoted more "automatic" processing and, as such, presented no difficulty for the RBD patients in the use of contextual information.

An obvious objection to this explanation, however, relates to the fact that the tasks used by Leonard et al. (1997a, 1997b) were not "automatic" in the sense of being on-line and were thus not a reflection of initial first-pass processing. The tasks were argued to be automatic only in the sense that the process of determining coreference is a natural, "automatic" language process and that the processing demands of the task were relatively low given that, at most, the stimuli consisted of two sentences. Consequently, the claim that RBD patients can use contextual information during on-line, automatic processing requires further empirical validation.

The goal of the present study was, thus, to systematically evaluate the aforementioned claim. The task and stimuli used were patterned after those used by MarslenWilson and Tyler (1980), who used a word-monitoring task to investigate the effects of context on word recognition. In Marslen-Wilson and Tyler's study, subjects were required to monitor for an auditorily presented target word and respond when it was heard. The target word (underlined in the following examples) was presented in three types of stimulus sentences-Normal Prose, wherein both a syntactic and semantic analysis of the string was possible (e.g., Some thieves stole most of the lead off the roof); Anomalous Prose, which consisted of a string of words for which syntactic structuring was possible but which was semantically uninterpretable (e.g., No buns puzzle some in the lead off the text); and Scrambled Prose, which consisted of an unstructured list of words (e.g., Some the no puzzle buns in lead text the off). The position of the target words in the test sequences was also varied in order to track the development of sources of contextual constraint across the sentence.

In the first experiment, a Normal, Anomalous, or Scrambled prose lead-in sentence was used (e.g., "The church was broken into last week," "The power was located in great water," "In was great power water the located"). Results indicated that reaction times were faster to target words in the Normal Prose than in the Anomalous Prose condition and faster in the Anomalous Prose than in the Scrambled Prose condition. Of particular interest was the finding that the position of the target word had no effect in the Scrambled Prose condition yet did affect reaction times in both the Normal Prose and Anomalous Prose conditions. Under both conditions, reaction times decreased as the target word moved from the first to the tenth word position. Interestingly, the magnitude of difference in reaction times to target words under the Normal Prose versus the Anomalous Prose conditions remained the same at each target word position in the sentence. In particular, it was interesting 
to note that the difference in reaction times was just as great at the beginning of the sentence as at the end of it. The authors hypothesized, therefore, that the advantage of the Normal Prose condition over the Anomalous Prose condition was due to the semantic information available under the Normal Prose condition. Moreover, because the first few words of an utterance are not sufficient in providing the same degree of interpretative power as would be obtained in the latter part of a sentence, it was reasoned that facilitation must have been provided by the information contained in the leadin sentence. In order to check this hypothesis, a second experiment was conducted that used the exact same stimuli except that the lead-in sentence was omitted. The effect of this manipulation was that the advantage in the Normal Prose condition early in the sentence essentially disappeared. These results were interpreted as support for the use of discourse context in word recognition. In fact, the influence of context on word recognition and syntactic processing is quite robust and has been demonstrated by a number of studies (e.g., Paul, Kellas, Martin, \& Clark, 1992; Steedman \& Altmann, 1989), although the time course of activation of contextual information certainly remains a contentious issue (Marslen-Wilson \& Tyler, 1987; Simpson, 1994).

As noted above, the present study also used a wordmonitoring task. Pairs of sentences were auditorily presented to subjects who were required to respond as quickly as possible when a target word was heard. Stimuli were similar to those used in Marslen-Wilson and Tyler (1980) in that both normal and semantically anomalous target and lead-in sentences were used. Scrambled prose stimuli were not included because sensitivity to syntactic context was not of particular interest for this population. The effect of word position was investigated by locating the target word in three different positions (end, middle, and beginning). Context effects similar to those found by Marslen-Wilson and Tyler (1980) were expected. Critical to the issue regarding the use of context by RBD patients was the question of whether or not they would also show normal effects of context and thereby support the claim that RBD patients can use contextual information during on-line automatic processing (Leonard et al., 1997a, 1997b; Tompkins, 1990; Tompkins et al., 1992).

\section{RESULTS}

The experiment used a mixed design with one between groups factor and three within groups factors. The between groups factor was Group with two levels-RBD and non-brain-damaged (NBD). The within groups factors were Position, with three levels-end, middle, and beginning; Context, with two levels-normal and anomalous; and Target, also with two levels-normal and anomalous.

An analysis of variance with subjects as a random factor was performed on the mean reaction times. ${ }^{1}$ Ex- treme reaction time values, defined as those values less than or greater than the condition mean \pm 2 standard deviations, were not included in the analysis. Also, reaction times greater than 5 sec were automatically timed out and excluded from the analysis. All pairwise comparisons were done using the Newman-Keuls procedure $(p<0.05)$. Only significant effects will be reported.

Table 1 shows the mean reaction times (in milliseconds) and the standard error values per condition for each group. Analysis of the data revealed a significant main effect of Target $(F(1,18)=46.33, p<0.001)$, with faster reaction times to normal target sentences (mean $=344 \mathrm{msec}$ ) than to anomalous target sentences $($ mean $=438 \mathrm{msec})$. The Group $\times$ Target interaction was also found to be significant $(F(1,18)=4.5, p<0.05)$. An analysis of simple main effects proved uninteresting, indicating simply that the NBD group was significantly faster than the RBD group when responding to anomalous target sentences but not to normal target sentences. Importantly, both groups responded faster to normal than anomalous target sentences.

The interaction of Position $\times$ Context was also found to be significant $(F(2,36)=3.68, p<0.05)$. Pairwise comparisons revealed that when the target word was at both the end and middle positions in the target sentence, there was no difference in reaction times to targets when preceded by a normal or anomalous leading (context) sentence. On the other hand, when the target word was at the beginning of the target sentence, reaction times to targets preceded by a normal leading sentence were faster $($ mean $=378 \mathrm{msec})$ than to those preceded by an anomalous leading sentence (mean $=458 \mathrm{msec}$ ). Also, the pairwise comparisons revealed that with a normal leading sentence there was no effect of position. However, with an anomalous leading sentence, reaction times to target words in the beginning position (mean = $458 \mathrm{msec}$ ) were slower than to those in both the middle $($ mean $=379 \mathrm{msec})$ and end $($ mean $=381 \mathrm{msec})$ positions, which, in turn, were not significantly different from each other.

Inspection of the individual data revealed that the finding of faster reaction times to words in the beginning position preceded by a normal versus an anomalous context was demonstrated by $70 \%$ of individuals in both the NBD and RBD groups. Interestingly, faster reaction times to normal versus anomalous context sentences was also found for $60 \%$ of the individuals in the RBD group for both the middle and end positions but only for $20 \%$ and $40 \%$ of individuals in the NBD group for these positions, respectively. In fact, closer inspection of the individual data for this effect showed inconsistent patterns of performance for both groups, suggesting that this effect was not particularly revealing.

A significant Position $\times$ Target interaction was also found $(F(2,36)=9.37, p<0.001)$. Pairwise comparisons indicated that when the target word was at the end or middle position of the target sentence, responses to 
Table 1. Mean Reaction Times (msec) and Standard Error Values (in parentheses)

\begin{tabular}{|c|c|c|c|c|}
\hline \multirow[b]{2}{*}{ Position } & \multirow[b]{2}{*}{ Context } & \multirow[b]{2}{*}{ Target } & \multicolumn{2}{|c|}{ Group } \\
\hline & & & $N B D$ & $R B D$ \\
\hline \multirow[t]{4}{*}{ End } & Normal & Normal & 276 (16) & $360(46)$ \\
\hline & Normal & Anomalous & 362 (19) & $497(71)$ \\
\hline & Anomalous & Normal & 288 (18) & $392(57)$ \\
\hline & Anomalous & Anomalous & 347 (18) & $494(87)$ \\
\hline \multirow[t]{4}{*}{ Middle } & Normal & Normal & 243 (29) & 321 (39) \\
\hline & Normal & Anomalous & $386(26)$ & 557 (106) \\
\hline & Anomalous & Normal & $248(17)$ & 407 (77) \\
\hline & Anomalous & Anomalous & 321 (18) & $539(89)$ \\
\hline \multirow[t]{4}{*}{ Beginning } & Normal & Normal & 296 (19) & 406 (69) \\
\hline & Normal & Anomalous & 317 (14) & $493(75)$ \\
\hline & Anomalous & Normal & 330 (19) & $557(140)$ \\
\hline & Anomalous & Anomalous & $339(21)$ & 605 (143) \\
\hline
\end{tabular}

normal target sentences were faster than to anomalous target sentences (means are as follows: end normal $=329$ msec, end anomalous $=425$ msec $;$ middle normal $=305$ msec, middle anomalous $=451 \mathrm{msec}$ ). This difference in reaction times to target words in normal and anomalous target sentences did not hold when the target word was at the beginning position. In addition, the pairwise comparisons indicated that there was an effect of position for normal target sentences such that responses were slower to target words in the beginning position (mean $=397 \mathrm{msec})$ compared to those both in the middle $($ mean $=305 \mathrm{msec})$ and end $($ mean $=329 \mathrm{msec})$ positions, which were not significantly different from each other. This effect of position did not hold for anomalous target sentences.

Figure 1 represents the mean percentage decrease in reaction times to normal versus anomalous target sentences [i.e., $(A-N) / A$ ] at each position for the individual members of each group. A positive value indicates that reaction times were faster to normal than to anomalous sentences and a negative value indicates the reverse. As is obvious from the figure, $90 \%$ of the NBD group and $70 \%$ of the RBD group demonstrated a greater mean percentage decrease in reaction times to normal versus anomalous sentences for both the end and middle positions as compared to the beginning position, consistent with the group effect. A review of the individual characteristics of the RBD patients who did not demonstrate this pattern (i.e., 2, 3, and 10) reveals no obvious common denominator except, perhaps, that patients 2 and 10 both had subcortical lesions.

Finally, a significant Context $\times$ Target interaction was also found $(F(1,18)=19.05, p<0.001)$. Pairwise comparisons revealed that in the context of both normal and anomalous leading sentences, reaction times to target words in normal target sentences (means $=317$ and 371 msec, respectively) were faster than to those in anomalous target sentences (means $=435$ and $441 \mathrm{msec}$, respectively). Inspection of the individual data revealed that this finding was quite robust because it was found to be consistent across all members of each group. The interaction arose from the fact that reaction times to target words were faster when preceded by a normal than an anomalous leading sentence for the normal (means $=317$ vs. $371 \mathrm{msec}$ ), but not the anomalous (means $=435$ vs. $441 \mathrm{msec}$ ), target sentences. Once again, inspection of the individual data revealed a consistent pattern of performance across individual members of each group. Eighty percent of the members of both the NBD and RBD groups showed greater facilitation to normal versus anomalous context sentences for normal as compared to anomalous target sentences. Once again, inspection of the individual characteristics of the two patients who did not conform to the group pattern (patients 3 and 5) reveals no outstanding factor to account for their performance.

\section{DISCUSSION}

This study was conducted to investigate the on-line influence of context on word recognition. Of particular interest was the question concerning whether or not RBD individuals would demonstrate the ability to use contextual information, consistent with previous investigations (e.g., Leonard et al., 1997a, 1997b). In fact, the results are quite revealing in a number of ways.

First of all, it is important to note that the results of this investigation add further support for the current 
Figure 1. Mean percentage decrease in RT to Normal versus Anomalous target sentences

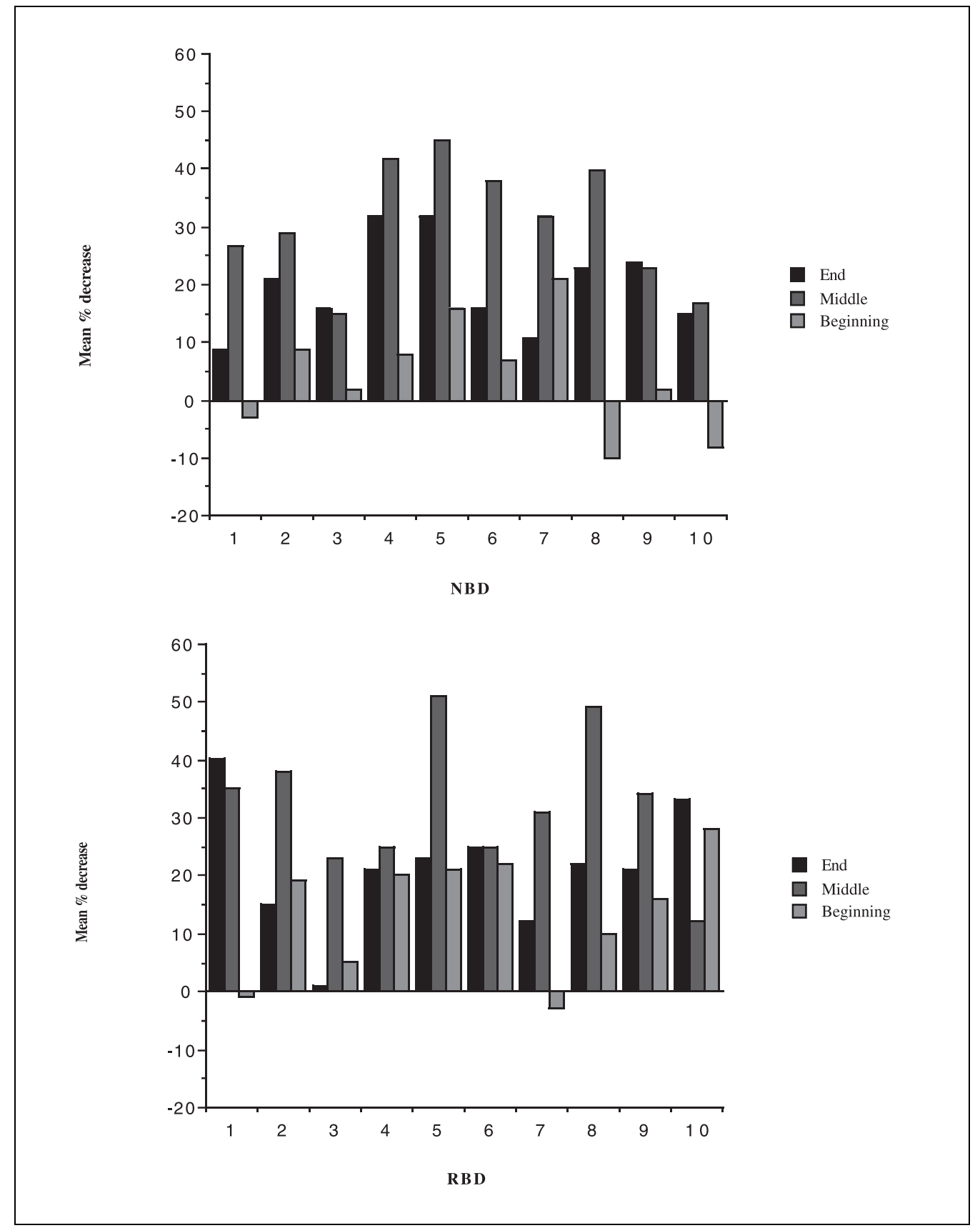

view that contextual information does influence word recognition at some point in the process (MarslenWilson \& Tyler, 1987). Effects of context were found at a number of levels. For instance, the finding that reaction times to target words were faster when preceded by a normal versus an anomalous context only when the target word was in the beginning position of the target sentence suggests that information in the leading sentence facilitated word recognition. However, when the target word was located at a later position in the sentence, the contextual information found in the leading sentence was no longer influential, as reflected in the failure to find an effect of context at the middle and end positions. As noted earlier, however, inspection of the individual data for this effect showed inconsistent performance across members of both groups; thus, this result should be interpreted with caution.

A more consistent and robust demonstration of contextual influences is found in the Position $\times$ Target interaction. Reaction times were faster to normal versus anomalous target sentences only when the target word was in the middle or end position. This effect is in keeping with the findings of Marslen-Wilson and Tyler (1980) and suggests that the advantage in reaction times to normal versus anomalous target sentences may be attributed to the build-up of semantic information as the sentence was processed, because both sentence types respected the syntactic rules of English. Obviously, the 
influence of semantic information in the normal sentences would not be effective for target words in the beginning position of the sentence, and this is reflected in the failure to find an effect of target sentence type at that position. Particularly striking was the finding that this pattern of performance was demonstrated by the majority of individuals in both the NBD and RBD groups, indicating that RBD patients are sensitive to the build-up of semantic context in on-line processing.

The influence of contextual information on word recognition was also strongly indicated by the finding that all members of each group responded faster to target words in normal than anomalous target sentences in the contexts of both normal and anomalous leading sentences. Interestingly, the information contained in the leading sentence also appeared to facilitate word recognition as reflected in faster reaction times to target words preceded by a normal versus anomalous leading sentence, but only when the target sentence was also normal. This finding suggests that the semantic integrity of the contextual information that is most closely associated temporally to the target word is most important in influencing the word-recognition process. Attestation to the strength of this effect is found once again in the inspection of the individual data, which revealed that this pattern of performance was demonstrated by the majority of individuals in both groups.

With regard to the major focus of this investigationthat is, whether or not RBD individuals would demonstrate normal effects of context-the results are quite clear. The failure to find an interaction between Group and any of the other factors (with the exception of Target which, as indicated in the analysis of simple main effects, proved uninteresting) suggests that the RBD individuals were similar to normals in responding to the contextual information available. These results support those of Leonard et al. (1997a, 1997b), which demonstrated that RBD patients could use contextual information to resolve ambiguous pronouns. Importantly, the present findings show that, in a task tapping on-line processing, RBD patients utilize contextual information, validating the suggestion made by Leonard et al. (1997a, 1997b) that context effects emerge for RBD individuals in tasks that promote more automatic processing. Recall that in Leonard et al. the tasks were not automatic in the sense of being on-line and, therefore, did not reflect first-pass processing. In contrast, the word-monitoring task used in the present investigation is believed to support automatic processing. Thus, the finding of a context effect by RBD patients with such a task provides empirical support for the view that RBD patients do not present with a specific deficit in the use of contextual information. Rather, consistent with the claim of Tompkins and her colleagues (e.g., Tompkins, 1991; Tompkins et al., 1992), it is argued that when processing demands are low, RBD patients are able to use contextual information. Moreover, it is also important to note that the majority of the patients tested had deficits in other discourse-level skills such as inferencing and the processing of figurative language. Thus, one cannot argue that these subjects merely represented a subset of RBD individuals who did not present with discourse-level deficits and hence would not be expected to evidence a deficit in context use.

The present results, in conjunction with those of Leonard et al. (1997a, 1997b) and Tompkins and colleagues (e.g., Tompkins, 1990, 1991; Tompkins et al., 1992; Tompkins \& Flowers, 1987), clearly support one aspect of Tompkins' position that a proposed impairment in the use of contextual information by RBD patients is a function of task demands. That is, there is accumulating evidence to suggest that when processing demands are reduced, RBD patients can effectively use contextual information. A critical aspect of this position that remains to be verified, however, is the claim that as processing demands increase, impairments in the use of contextual information will emerge in RBD patients. According to Tompkins (1990; Tompkins \& Flowers, 1987), this is what is hypothesized to be occurring when patients demonstrate deficits in discourse-level tasks of story retelling and inferencing of morals as in Wapner, Hamby, and Gardner (1981), for example. However, such tasks tap quite different abilities and do not reflect a straightforward increase in task demands. It is imperative, therefore, that future investigations systematically explore this claim, perhaps through the use of a dual task paradigm. Dual task paradigms involve simultaneously engaging the subject in a second unrelated task (such as tracking a target on a computer screen) while he or she is performing the experimental task (such as word monitoring). Dual tasks are believed to increase processing demands in that both tasks are competing for a limited set of processing resources. If Tompkins' claim is correct, it is expected that RBD patients would demonstrate an impairment in the use of contextual information under a dual task condition. Such a finding would empirically support the view that RBD patients are vulnerable to deficits in the use of contextual information only as the processing demands of the task are sufficiently increased.

As an aside, it should be noted that the foregoing discussion parallels recent findings in the aphasia literature that have suggested that reduced processing resources may also account for certain language deficits in aphasia (e.g., Caplan \& Waters, 1995; Miyake, Carpenter, \& Just, 1994). Some may argue, therefore, that the notion that brain damage results in effortful tasks being more difficult is uninteresting. However, the point that must be considered, and that speaks to the issue of hemispheric specialization for language, is that increased processing demands appear to differentially affect the components of language that are impaired as a function of right- versus left-brain damage. Specifically, the processing of syntax and semantics are generally vulnerable 
to left-brain damage, whereas the processing of discourse (i.e., context use) is vulnerable to right-brain damage.

Before concluding, two caveats must be offered. The first concerns the fact that none of the effects reported were consistent when using items as a random factor. This suggests that the effects did not hold across all items, and therefore, one must be cautious in generalizing the results beyond the items tested (Leonard \& Orchard, 1996). The second caveat concerns the fact that the claim that RBD patients performed similarly to normals is based on the interpretation of a null result. Of course, as with all statistical analyses, one must be cautious in interpreting null results. One might argue that the failure to find an interaction with Group was simply due to the fact that the sample sizes were relatively small. In principle, this objection is valid; however, upon consideration of the individual data, it is not likely. Patterns of performance indicative of the use of contextual information were found to be characteristic of the majority of individuals in both the NBD and RBD groups.

In sum, these results support the prevailing view that contextual information is influential in word recognition (e.g., Paul et al., 1992; Steedman \& Altmann, 1989). Moreover, particularly interesting to the purpose of this study was the demonstration that RBD individuals performed similarly to normals in using context. This finding, although discrepant with the view held by many that RBD patients have deficits in the use of contextual information in language processing (e.g., Cook, 1989; Gardner et al., 1983), is certainly consistent with the more recent findings of Leonard et al. (1997a, 1997b). Importantly, the on-line use of context by RBD patients partially supports the view of Tompkins and her colleagues (e.g., Tompkins, 1990; Tompkins et al., 1992) that deficits in the use of context by RBD patients may only emerge as a function of increased processing demands. When task demands are relatively low and on-line processing is tapped (as with the word-monitoring task used in the present investigation), RBD patients do not exhibit deficits in the use of contextual information. Future investigations should focus on investigating the effects of increased processing demands on the ability of RBD patients to use contextual information in tasks assessing similar linguistic processes.

\section{METHOD}

\section{Subjects}

Two groups of subjects were tested (see Table 2). The RBD group consisted of 10 individuals (mean age: 65 years; mean level of education: 12 years) recruited from a number of institutions in the Montreal area. Initial exclusionary criteria included the presence of multiple infarcts, a known history of drug or alcohol abuse, and a known history of psychiatric and/or other neurological
Table 2a. RBD Subject Information

\begin{tabular}{|c|c|c|c|c|}
\hline Patient & $\begin{array}{c}\text { Age } \\
\text { (years) }\end{array}$ & $\begin{array}{c}\text { Education }^{a} \\
\text { (years) }\end{array}$ & Sex & $\begin{array}{c}\text { Site of Lesion } \\
\text { (acc. to CT Scan) }\end{array}$ \\
\hline 1 & 74 & 10 & M & Right parietal \\
\hline 2 & 68 & 18 & $\mathrm{~F}$ & $\begin{array}{l}\text { Internal capsule and } \\
\text { corona radiata }\end{array}$ \\
\hline 3 & 69 & $\mathrm{NA}^{b}$ & M & $\begin{array}{l}\text { Right temporo- } \\
\text { parieto-occipital }\end{array}$ \\
\hline 4 & 54 & 12 & $\mathrm{~F}$ & $\begin{array}{l}\text { Right posterior } \\
\text { communicating } \\
\text { artery; } \\
\text { subarachnoid } \\
\text { hemorrhage }\end{array}$ \\
\hline 5 & 66 & NA & $\mathrm{F}$ & Right $\mathrm{MCA}^{c}$ \\
\hline 6 & 59 & 14 & $\mathbf{M}$ & $\begin{array}{l}\text { Right temporo- } \\
\text { parieto-occipital; } \\
\text { hemorrhage }\end{array}$ \\
\hline 7 & 29 & 13 & $\mathrm{~F}$ & Right MCA \\
\hline 8 & 83 & 5 & $\mathrm{~F}$ & $\begin{array}{l}\text { Right MCA; } \\
\text { hemorrhage }\end{array}$ \\
\hline 9 & 86 & 12 & $\mathrm{~F}$ & NA \\
\hline 10 & 62 & NA & $\mathrm{F}$ & External capsule \\
\hline Mean & 65 & 12 & & \\
\hline
\end{tabular}

$a$ Best estimated conversion into years, based on information from subject (e.g. 2 years college, high school).

${ }^{b}$ Information not available;

${ }^{c}$ Middle cerebral artery.

Table 2b. NBD Subject Information

\begin{tabular}{lccc}
\hline Subject & Age (years) & $\begin{array}{c}\text { Education }^{a} \\
\text { (years) }\end{array}$ & Sex \\
\hline 1 & 63 & 12 & $\mathrm{M}$ \\
2 & 72 & 16 & $\mathrm{M}$ \\
3 & 68 & 11 & $\mathrm{~F}$ \\
4 & 61 & 16 & $\mathrm{~F}$ \\
5 & 62 & $\mathrm{NA}^{b}$ & $\mathrm{~F}$ \\
6 & 70 & 15 & $\mathrm{M}$ \\
7 & 72 & 18 & $\mathrm{M}$ \\
8 & 69 & 18 & $\mathrm{~F}$ \\
9 & 65 & 18 & $\mathrm{~F}$ \\
10 & 59 & 12 & $\mathrm{M}$ \\
Mean & 66 & 15 & \\
\hline
\end{tabular}

${ }^{a}$ Best estimated conversion into years, based on information from subject (e.g. 2 years college, high school).

${ }^{b}$ Information not available. 
illness. Lesion sites were determined based on neurological reports and Computerized Cranial Tomography (CT) scans when available. All patients had suffered a single cerebrovascular accident at the time of testing and were at least 4 months postonset. Lesions were primarily cortical with the exception of two patients, who evidenced subcortical lesions. Based on available reports, none of the RBD patients presented with any obvious aphasic deficits.

A test battery (adapted from the Test of Language Competence-Expanded Edition, Wiig \& Secord, 1987) assessing patients' abilities to make inferences and to comprehend figurative language (skills frequently impaired in RBD patients) was administered. Two of the patients (2 and 7) presented with no significant deficits in these areas. Of the remaining eight, six presented with impairments in inferencing (patients 1, 5, 6, 8, 9, and 10), and all had deficits in the comprehension of figurative language. Patients were also screened on the Bells Test for visual neglect (Gauthier, Dehaut, \& Joanette, 1989) and the Auditory Sentence Comprehension Test-a subtest of the Psycholinguistic Assessment of Language (Caplan, 1992). A summary of the patients' performances on the screening tests is presented in Table 3. Hearing was also screened and found to be within normal limits.

The NBD group consisted of 10 individuals (mean age: 66 years; mean level of education: 15 years) chosen from a large number of volunteers in the Montreal area. None of the subjects had a known history of neurological or psychiatric illness. All control subjects passed a series of neuropsychological tests that included the Boston Naming Test (Kaplan, Goodglass, \& Weintraub, 1983), a modified version of the Mini-Mental State Examination

Table 3. Summary of Performances on Screening Tests ${ }^{a}$

\begin{tabular}{lcccc}
\hline Patient & $I N F / 10$ & $F I G / 10$ & $B T / 35$ & $A S C / 40$ \\
\hline 1 & 7 & 2 & $\mathrm{DNA}^{b}$ & 34 \\
2 & 9 & 9 & 35 & DNA \\
3 & 9 & 7 & $31^{c}$ & 36 \\
4 & 10 & 8 & 34 & 40 \\
5 & 8 & 3 & $20^{d}$ & DNA \\
6 & 5 & 6 & $22^{d}$ & DNA \\
7 & 10 & 9 & 35 & $18 / 20$ \\
8 & 7 & 8 & $16^{d}$ & 31 \\
9 & 7 & 4 & $27^{c}$ & 38 \\
10 & 7 & 4 & $22^{d}$ & DNA \\
\hline
\end{tabular}

${ }^{a}$ INF (Test of Inferencing); FIG (Test of Figurative Language); BT (Bells Test); ASC (Auditory Sentence Comprehension Test)

${ }^{b}$ Did not administer.

${ }^{c}$ Attentional deficit likely.

${ }^{d}$ Neglect likely.
(Folstein, Folstein, \& McHugh, 1975), and the Logical Memory subtests (Immediate and Delayed) of the Wechsler Memory Scale-Revised (Wechsler, 1987) to rule out the possibility of disorders such as dementia.

\section{Materials}

The stimuli consisted of sentence pairs. Three factors were manipulated in the construction of the stimuli. The first factor, termed Position, related to the position of the target word in the second (10-word) sentence of the pair. It had three levels-end (word position 8 to 10), middle (word position 5 to 7 ), and beginning (word position 2 to 4$)$. The second factor, Context, which related to the status of the leading sentence, had two levels-normal and anomalous. The third factor, Target, related to the status of the second sentence and it also had two levels-normal and anomalous. For both the factors Context and Target, the normal sentences were normal both syntactically and semantically. The anomalous sentences, on the other hand, although respecting the syntactic rules of English, were semantically anomalous. They were constructed by changing the content words (except for the target word) in the normal sentences, respecting word class and word frequency as much as possible (e.g., "They were relieved to find that a store was near" became "They were impressed to feel that a store was gradual"). Words that were not changed included articles, the "to" of infinitive verbs, "be" forms, conjunctions, pronouns, proper nouns, qualifiers (e.g., very, extremely), prequantifiers (e.g., many, all), WH-adverbs (e.g., when), negatives, "have been" forms, and past tense of "have."

The normal context (i.e., leading) sentences were all contextually supportive of the target word. On the other hand, in the normal target sentences the target word was not predictable based on the target sentence alone. The predictability of the target words based on the normal context and normal target sentences was determined by a pilot study. Subjects were given, in written form, either the context sentence plus the target sentence fragment up to the target word (e.g., "Mary was afraid to enter the cold dark cellar alone. She was very glad to discover the "), or the target sentence fragment (with no context sentence) up to the target word alone, and were required to fill in the blank with the first word that came to mind. Based on target sentence fragments alone, the target word was chosen less than $50 \%$ of the time. In contrast, with the addition of the context sentence, the target word was chosen at least $60 \%$ of the time.

Target words were all monosyllabic and none was repeated in the context sentence. Word frequency of the target words was approximately equally balanced across positions (mean frequencies: end, 182; middle, 184; beginning, 188).

There were 10 different target words in each position resulting in a total of 30 target words. Furthermore, for 
each target word, a pair of sentences consisting of a normal context sentence and a normal target sentence and another pair of sentences consisting of an anomalous context sentence and an anomalous target sentence were constructed. In turn, each normal context sentence was paired with its respective anomalous target sentence and each anomalous context sentence was paired with its respective normal target sentence, resulting in a total of 120 stimulus pairs (see Table 4).

The stimuli were recorded by an adult male native speaker of English and digitized at a rate of 10k samples per second with a $4.5-\mathrm{kHz}$ low-pass filter and 12-bit quantization. Stimulus files were created as follows: First the target word was presented, followed 500 msec later by the context sentence and then $100 \mathrm{msec}$ later by the target sentence. The intertrial interval was $5 \mathrm{sec}$. Timing of responses began as soon as the target word appeared. Reaction times (in milliseconds) were recorded by the computer.

\section{Procedure}

The stimuli were divided into four blocks with only one instance of each target word represented in each block. The sentences within each block were presented in a fixed random order and the order of presentation of the blocks was semi-counterbalanced across subjects. The interblock interval was $10 \mathrm{sec}$. Eight practice trials preceded the presentation of the experimental stimuli.

The stimuli were presented over headphones to subjects seated in front of a response board. They were instructed that they would be hearing a target word followed by two sentences. Their task was to listen for the target word in the following two sentences and to press the response button as soon as they heard the word. The target word was also printed on a card to

Table 4. Examples of Stimuli ${ }^{a}$

ENN Tim was experiencing a considerable amount of trouble walking home.

The terrible pain was getting increasingly worse in his foot.

ENA Tim was experiencing a considerable amount of trouble walking home.

The remarkable hotel was doing increasingly wild to his foot.

EAN Tim was kissing a proper wall in treatment showing today.

The terrible pain was getting increasingly worse in his foot.

EAA Tim was kissing a proper wall in treatment showing today.

The remarkable hotel was doing increasingly wild to his foot.

${ }^{a} \mathrm{E}=$ end $; \mathrm{N}=$ normal $; \mathrm{A}=$ anomalous. make it easier for the subjects to remember it. They were further alerted to the fact that some of the sentences would not make any sense.

\section{Acknowledgments}

This research was supported by team grants from the Fonds pour la Formation de Chercheurs et l'Aide à la Recherche (FCAR) du Québec and the Fonds de la Recherche en Santé du Québec (FRSQ).

Reprint requests should be sent to Shari Baum, School of Communication Sciences and Disorders, McGill University, 1266 Pine Avenue West, Montreal, Quebec, H3G 1A8.

\section{Note}

1. An analysis of variance with items as a random factor was also performed. Only the main effect of Group was significant $(F(1,108)=186.6 \mathrm{p}<0.001)$.

\section{REFERENCES}

Bihrle, A. M., Brownell, H. H., Powelson, J., \& Gardner, H. (1986). Comprehension of humorous and nonhumorous materials by brain-damaged patients. Brain and Cognition, 5, 399-411.

Brownell, H., Gardner, H., Prather, P., \& Martino, G. (1995). Language, communication, and the right hemisphere. In H. S. Kirshner (Ed.), Handbook of neurological speech and language disorders (pp. 325-349). New York: Marcel Dekker.

Brownell, H. H., Simpson, T. L., Bihrle, A. M., Potter, H. H., \& Gardner, H. (1990). Appreciation of metaphoric alternative word meanings by left and right brain-damaged patients. Neuropsychologia, 28, 375-383.

Caplan, D. (1992). Language: Structure, process, and disorders (pp. 403-441). Cambridge, MA: MIT Press.

Caplan, D. \& Waters, G. S. (1995). Aphasic disorders of syntactic comprehension and working memory capacity. Cognitive Neuropsychology, 12, 637-649.

Caramazza, A., Grober, E., Garvey, C., \& Yates, J. (1977). Comprehension of anaphoric pronouns. Journal of Verbal Learning and Verbal Behavior, 16, 601-609.

Cook, N. D. (1989). Toward a central dogma for psychology. New Ideas in Psychology, 7, 1-18.

Folstein, M. F., Folstein, S. E., \& McHugh, P. R. (1975). "Minimental state": A practical method for grading the cognitive state of patients for the clinician. Journal of Psychiatric Research, 12, 189-198.

Gagnon, J., Goulet, P., \& Joanette, Y. (1994). Activation of the lexical-semantic system in right brain-damaged righthanders. In D. Hilt (Ed.), Linguistic and cognitive neuroscience: Theoretical and empirical studies in language disorders (pp. 33-48). Opladen, Germany: Westdeutscher Verlag.

Gardner, H., Brownell, H., Wapner, W., \& Michelow, D. (1983). Missing the point: The role of the right hemisphere in the processing of complex linguistic materials. In E. Perecman (Ed.), Cognitive processing in the right hemisphere (pp. 169-191). New York: Academic Press.

Gauthier, L., Dehaut, F, \& Joanette, Y. (1989). The Bells Test: A quantitative and qualitative test for visual neglect. International Journal of Clinical Neuropsychology, 11, 49-54.

Hirst, W., \& Brill, G. A. (1980). Contextual aspects of pronoun 
assignment. Journal of Verbal Learning and Verbal Behavior, 19, 168-175.

Hough, M. S. (1990). Narrative comprehension in adults with right and left hemisphere damage: Theme organization. Brain and Language, 38, 253-277.

Joanette, Y., \& Goulet, P. (1990). Narrative discourse in rightbrain-damaged right-handers. In Y. Joanette \& H. H. Brownell (Eds.), Discourse ability and brain damage: Theoretical and empirical perspectives (pp. 131-153). New York: Springer Verlag.

Joanette, Y., Goulet, P., \& Hannequin, D. (1990). Right bemisphere and verbal communication. New York: Springer Verlag.

Kaplan, J. A., Brownell, H. H., Jacobs, J. R., \& Gardner, H. (1990). The effects of right hemisphere damage on the pragmatic interpretation of conversational remarks. Brain and Language, 38, 315-333.

Kaplan, E., Goodglass, H., \& Weintraub, S. (1983). Boston Naming Test. Philadelphia: Lea \& Febiger.

Leonard, C. L., \& Orchard, D. (1996). The problem of generalizing to a language population: A "random" controversy. Journal of Speech and Hearing Research, 39, 406-413.

Leonard, C. L., Waters, G. S., \& Caplan, D. (1997a). The use of contextual information by right brain-damaged individuals in the resolution of ambiguous pronouns. Brain and Language, 57, 309-342.

Leonard, C. L., Waters, G. S., \& Caplan, D. (1997b). The use of contextual information related to general world knowledge by right brain-damaged individuals in pronoun resolution. Brain and Language, 57, 343-359.

Marslen-Wilson, W. D., \& Tyler, L. K. (1980). The temporal structure of spoken language understanding. Cognition, 8, $1-71$.

Marslen-Wilson, W., \& Tyler, L. K. (1987). Against modularity. In J. L. Garfield (Ed.), Modularity in knowledge representation and natural language understanding (pp. 3762). Cambridge, MA: MIT Press.

Miyake, A., Carpenter, P. A., \& Just, M. A. (1994). A capacity approach to syntactic comprehension disorders: Making normal adults perform like aphasic patients. Cognitive Neuropsychology, 11, 671-717.

Paul, S. T., Kellas, G., Martin, M., \& Clark, M. B. (1992). The influence of contextual features on the activation of am- biguous word meanings. Journal of Experimental Psychology: Learning, Memory, and Cognition, 18, 703-717.

Schneiderman, E. I., Murasugi, K. G., \& Saddy, J. D. (1992). Story arrangement ability in right brain-damaged patients. Brain and Language, 43, 107-120.

Simpson, G. B. (1994). Context and the processing of ambiguous words. In M. A. Gernsbacher (Ed.), Handbook of psycholinguistics (pp.359-374). San Diego: Academic Press.

Steedman, M., \& Altmann, G. (1989). Ambiguity in context: A reply. Language and Cognitive Processes, 4, 105-122.

Tompkins, C. A. (1990). Knowledge and strategies for processing lexical metaphor after right or left hemisphere brain damage. Journal of Speech and Hearing Research, 33, 307-316.

Tompkins, C.A. (1991). Redundancy enhances emotional inferencing by right- and left-hemisphere-damaged adults. Journal of Speech and Hearing Research, 34, 1142-1149.

Tompkins, C. A., Boada, R., \& McGarry, K. (1992). The access and processing of familiar idioms by brain damaged and normally aging adults. Journal of Speech and Hearing Research, 35, 626-637.

Tompkins, C. A., Bloise, C. G. R., Timko, M. L., \& Baumgaertner, A. (1994). Working memory and inference revision in braindamaged and normally aging adults. Journal of Speech and Hearing Research, 37, 896-912.

Tompkins, C. A., \& Flowers, C. R. (1987). Contextual mood priming following left and right hemisphere damage. Brain and Cognition, 6, 361-376.

Van Lancker, D. R., \& Kempler, D. (1987). Comprehension of familiar phrases by left- but not right-hemisphere damaged patients. Brain and Language, 32, 265-277.

Wapner, W., Hamby, S., \& Gardner, H. (1981). The role of the right hemisphere in the apprehension of complex linguistic materials. Brain and Language, 14, 15-33.

Wechsler, D. W. (1987). Wechsler Memory Scale-Revised. San Antonio: Harcourt, Brace, \& Jovanovich.

Weylman, S. T., Brownell, H. H., Roman, M., \& Gardner, H. (1989). Appreciation of indirect requests by left- and rightbrain-damaged patients: The effects of verbal context and conventionality of wording. Brain and Language, 36, 580-591.

Wiig, E. H., \& Secord, W. (1987). Test of language competence-Expanded edition. San Antonio: Harcourt, Brace, \& Jovanovich. 